\title{
Vitamin D deficiency and sufficiency among Canadian children residing at high latitude following the revision of the RDA of vitamin D intake in 2010
}

\author{
Lalani L. Munasinghe ${ }^{1}$, Yan Yuan ${ }^{1}$, Noreen D. Willows ${ }^{2}$, Erin L. Faught ${ }^{1}$, John P. Ekwaru ${ }^{1}$ and \\ Paul J. Veugelers ${ }^{1 *}$ \\ ${ }^{1}$ School of Public Health, University of Alberta, Alberta, Canada \\ ${ }^{2}$ Department of Agricultural, Food \& Nutritional Science, Faculty of Agriculture, Life and Environmental Sciences, University \\ of Alberta, Alberta, Canada, T6G1C
}

(Submitted 15 August 2016 - Final revision received 1 December 2016 - Accepted 27 January 2017 - First published online 1 March 2017)

\section{Abstract}

Recently, countries at high latitudes have updated their vitamin D recommendations to ensure adequate intake for the musculoskeletal health of their respective populations. In 2010, the dietary guidelines for vitamin D for Canadians and Americans aged 1-70 years increased from $5 \mu \mathrm{g} / \mathrm{d}$ to $15 \mu \mathrm{g} / \mathrm{d}$, whereas in 2016 for citizens of the UK aged $\geq 4$ years $10 \mu \mathrm{g} / \mathrm{d}$ is recommended. The vitamin D status of Canadian children following the revised dietary guidelines is unknown. Therefore, this study aimed to assess the prevalence and determinants of vitamin D deficiency and sufficiency among Canadian children. For this study, we assumed serum 25-hydroxy vitamin D (25(OH)D) concentrations $<30 \mathrm{nmol} / 1$ as 'deficient' and $\geq 50 \mathrm{nmol} / 1$ as 'sufficient'. Data from children aged 3-18 years $(n$ 2270) who participated in the 2012/2013 Canadian Health Measures Survey were analysed. Of all children, 5.6\% were vitamin D deficient and $71 \%$ were vitamin D sufficient. Children who consumed vitamin D-fortified milk daily ( $77 \%$ ) were more likely to be sufficient than those who consumed it less frequently (OR $2 \cdot 7 ; 95 \%$ CI 1.4, 5.0). The $9 \%$ of children who reported taking vitamin D-containing supplements in the previous month had higher $25(\mathrm{OH}) \mathrm{D}$ concentrations (OR $6.9 \mathrm{nmol} / 1 ; 95 \% \mathrm{CI} 1.1,12.7 \mathrm{nmol} / \mathrm{l}$ ) relative to those who did not. Children who were older, obese, of non-white ethnicity and from low-income households were less likely to be vitamin D sufficient. To improve vitamin D status, consumption of vitamin D-rich foods should be promoted, and fortification of more food items or formal recommendations for vitamin D supplementation should be considered.

\section{Key words: Vitamin D: Supplementation: Children: Dietary reference intake: Canadian Health Measure Survey: Determinants:} Canada

Although vitamin D deficiency is a health concern worldwide, vitamin D recommendations vary from country to country. It is possible to attain adequate vitamin $\mathrm{D}$ from cutaneous synthesis through exposure to solar radiation ${ }^{(1,2)}$; however, citizens living in high-latitude countries in North America ${ }^{(3-5)}$ and Europe ${ }^{(6)}$ are at risk of low vitamin $\mathrm{D}$ concentrations due to inadequate sun exposure ${ }^{(3,4,7)}$. Low dietary vitamin $\mathrm{D}$ intake due to the limited availability of vitamin D-rich natural foods ${ }^{(8)}$ and poor food choices ${ }^{(9-11)}$ compounds the situation. Therefore, food fortification together with supplementation are strategies suggested $^{(2,6,12-17)}$ for children and adults. However, milk and margarine are the only mandatorily vitamin D-fortified foods in Canada $^{(18)}$, and there are no formal guidelines for children $>1$ year to use vitamin D supplements. In the UK, dietary guidelines for vitamin D intake were not established until recently, because regular summer exposure to sunlight was considered adequate to synthesise enough vitamin $\mathrm{D}$ to meet year-round needs of citizens aged 4-64 years ${ }^{(19)}$. In the UK, margarine and infant formula are the only foods that are mandatorily fortified with vitamin $\mathrm{D}^{(6)}$, and therefore meeting vitamin $\mathrm{D}$ adequacy through diet alone may be challenging.

Because of increasing evidence of both skeletal ${ }^{(4,20)}$ and non-skeletal ${ }^{(4,7)}$ effects of vitamin D insufficiency, various health bodies have upwardly revised their vitamin $\mathrm{D}$ recommendations to ensure adequate intake. In 2016, the Scientific Advisory Committee on Nutrition recommended that everyone in the UK at 4 years of age and above consume $10 \mu \mathrm{g}$ of vitamin D daily. In 2010, the dietary intake of vitamin $\mathrm{D}$ for Americans and Canadians aged 1-70 years was increased from $5 \mu \mathrm{g} / \mathrm{d}$ as adequate intake to $15 \mu \mathrm{g} / \mathrm{d}$ as RDA, which is presumed to meet or exceed the vitamin D requirement of $97.5 \%$ of the healthy population. In the same year, the estimated average requirement (EAR) was established at $10 \mu \mathrm{g}$, which is estimated to meet the requirements of half of the population. The recommendations presume no or minimal sun exposure ${ }^{(20)}$.

Abbreviations: 25(OH)D, 25-hydroxy vitamin D; CHMS, Canadian Health Measures Survey; DRI, Dietary Reference Intake; MEC, mobile examination centre. 
Serum 25-hydroxy vitamin D $(25(\mathrm{OH}) \mathrm{D})$ concentration is the established biomarker for vitamin D status ${ }^{(4,21)}$, which reflects vitamin D derived from all sources, that is, diet, supplements and cutaneous synthesis $^{(4)}$. A daily intake of $15 \mu \mathrm{g}$ of vitamin $\mathrm{D}$ is linked to achieving a serum 25(OH)D concentration of $50 \mathrm{nmol} / \mathrm{l}$ and an intake of $10 \mu \mathrm{g}$ to achieving a serum $25(\mathrm{OH}) \mathrm{D}$ concentration of $40 \mathrm{nmol} / \mathrm{l}^{(20)}$. There is contention about the serum $25(\mathrm{OH}) \mathrm{D}$ concentration required for vitamin D sufficiency. In 2015, the Canadian Pediatric Society re-affirmed that 25(OH)D concentrations of $75 \mathrm{nmol} / 1$ are optimal for the prevention of a variety of childhood and adult diseases ${ }^{(22)}$. Furthermore, the Institute of Medicine ${ }^{(20)}$ has stated $30 \mathrm{nmol} / 1$ of serum $25(\mathrm{OH}) \mathrm{D}$ as the cut-off for vitamin D deficiency for Americans and Canadians, whereas the Scientific Advisory Committee on Nutrition in the $\mathrm{UK}^{(19)}$ recently decided to consider those with $25(\mathrm{OH}) \mathrm{D}$ concentrations $<25 \mathrm{nmol} / 1$ as deficient similar to the Canadian Pediatric Society's definition ${ }^{(22)}$. For the purpose of the present study, we assumed serum $25(\mathrm{OH}) \mathrm{D}$ concentrations $<30 \mathrm{nmol} / \mathrm{l}$ as deficient and $>50 \mathrm{nmol} / 1$ as sufficient.

Whiting et al. ${ }^{(13)}$ assessed the vitamin D status of Canadians aged 6-79 years based on serum vitamin D concentrations recommended by the 2010 Dietary Reference Intake (DRI) cut-offs of the Institute of Medicine ${ }^{(20)}$ using observations collected before 2010. They reported that $25.7 \%$ of Canadians had $25(\mathrm{OH}) \mathrm{D}<50 \mathrm{nmol} / \mathrm{l}$, with non-whites and non-supplement users having lower $25(\mathrm{OH}) \mathrm{D}$ concentrations, the latter especially in winter ${ }^{(13)}$. Sociodemographic indicators, food intake data and anthropometric variables were not examined in relation to vitamin D status. In addition, children were not examined separately from adults.

The vitamin D intake of children in some Canadian provinces is below the current EAR and $\mathrm{RDA}^{(23,24)}$. However, national data from the Canadian Health Measures Survey (CHMS) indicates that most children are vitamin D sufficient, considering that the average vitamin D concentration of children aged 6-11 years was $75 \mathrm{nmol} / 1$ in $2007-2009$ and $67 \mathrm{nmol} / 1$ in $2009-2011^{(12,25)}$. In contrast, based on the higher cut-off of $75 \mathrm{nmol} / 1$ for sufficiency suggested by the Canadian Pediatric Society, many Canadian children have inadequate vitamin D status. It is important to estimate the prevalence of vitamin D sufficiency and have a comprehensive understanding of risk factors for vitamin D insufficiency among Canadian children based on data obtained after 2010, in order to devise prevention strategies to protect against deficiency.

In this study, we aimed to identify the prevalence of vitamin D deficiency and sufficiency among Canadian children using data obtained from the nationally representative 2012/2013 CHMS. We extended this with prevalence estimates for surpassing other commonly used thresholds ( 40 and $75 \mathrm{nmol} / \mathrm{l}$ ). We further aimed to identify whether dietary, anthropometric, socio-demographic and seasonal factors were associated with serum 25(OH)D concentrations and vitamin D thresholds. Using this evidence, we aimed to determine which group of Canadian children is not meeting the thresholds for deficiency and sufficiency, and whether formal recommendations for vitamin $\mathrm{D}$ fortification and supplementation among children are required. This information might be useful for other countries in the northern hemisphere, considering whether food fortification or vitamin D supplementations should be considered for their populations.

\section{Methods}

Survey, sample design and participants

The CHMS is the most comprehensive, cross-sectional, direct health measures survey in Canada for individuals aged 3-79 years. It is led by Statistics Canada, in partnership with Health Canada and the Public Health Agency of Canada. The survey includes two parts - a home interview to gather demographic and in-depth health information, followed by the respondent's visit to a mobile examination centre (MEC) for direct physical measurements and biological specimen collection. All data were collected after receiving the participant's consent. A parent or guardian provided consent on behalf of children aged 3-13 years after receiving the child's assent to participate. Those aged 3-11 years were interviewed in the presence of a parent or guardian, who answered the questions with the assistance of the child. Additional information on the CHMS can be found on the Statistics Canada website (http://www.statcan.gc.ca).

To account for seasonality, data collection for CHMS (cycle 3) occurred from 9 January 2012 to 17 December 2013, representing Statistics Canada's standard regional boundaries: Atlantic Provinces (Nova Scotia, New Brunswick, Newfoundland and Labrador, Prince Edward Island), Quebec, Ontario, the Prairies (Alberta, Manitoba and Saskatchewan) and British Columbia. To produce reliable estimates at the national level by age group and sex, a multi-stage sampling design was used. The participants were distributed among six age groups (3-5, 6-11, 12-19, 20-39, 40-59 and $60-79$ years) and sex groups (except for $3-5$ years), for a total of eleven groups. For the 3-5-year age group, the survey was not designed to provide estimates for the individual's sex. Of the 360 eligible collection sites, sixteen were randomly selected using a systematic sampling method with probability proportional to each site's population size. Collection sites represented the Canadian population, east to west, with larger and smaller population densities. Next, dwellings were selected through random sampling followed by stratified sampling of inhabitants within the dwellings based on age groups ${ }^{(26,27)}$. Excluded from the survey's coverage were about $4 \%$ of the targeted population: residents living in certain remote regions, on First Nations reserves and Aboriginal settlements, full-time members of the Canadian Forces and the institutionalised population ${ }^{(26,27)}$. A detailed description of the CHMS sampling framework is given elsewhere ${ }^{(26,27)}$.

Out of 8302 individuals aged 3-79 years who were selected to participate in the survey, 7339 (88.4\%) completed the household interview and 5785 (78.8\%) later reported to the MEC. Of participants who attended the MEC, 5609 (97.0\%) were eligible to provide blood samples, whereas 176 were ineligible to provide blood samples because of medical reasons. Of the 5609 participants aged 3-79 years and eligible to provide blood, we excluded 3339 individuals. Among them were 3213 participants aged 19 years or older and 126 children who were pregnant or did not have enough blood drawn. We thus included data from 2270 children aged 3-18 years in the present study.

\section{Serum 25-hydroxy vitamin D measurement}

Serum 25(OH)D concentration in blood drawn from CHMS (cycle 3) participants was determined using the LIAISON $^{\circledR} 25(\mathrm{OH}) \mathrm{D}$ 
TOTAL assay on the Diasorin Liaison autoimmunoanalyzer (DiaSorin Ltd) using chemiluminescence immunoassay technology. The analytical detection limit was $10-375 \mathrm{nmol} / \mathrm{l}$. Serum $25(\mathrm{OH}) \mathrm{D}$ analysis is further described in the Vitamin D Reference Laboratory Standard Operating Procedures Manual ${ }^{28)}$. The between-run CV for the assay was $13.0 \%$. The CHMS reference laboratory precision targets for $<20,20-100$ and $>100 \mathrm{nmol} / \mathrm{l}$ were 15,10 and $12 \%$, respectively.

We defined 'vitamin D deficiency' as those with 25(OH)D concentrations $<30 \mathrm{nmol} / \mathrm{l}$ and 'meeting median requirement' as those with $\geq 40 \mathrm{nmol} / \mathrm{l}$ of $25(\mathrm{OH}) \mathrm{D}$. 'Vitamin D sufficiency' was defined using two serum $25(\mathrm{OH}) \mathrm{D}$ concentration cutoffs $-50 \mathrm{nmol} / 1$ recommended by the Institute of Medicine as an indication of achieving the RDA of $15 \mu \mathrm{g}^{(20)}$ and $75 \mathrm{nmol} / \mathrm{l}$ recommended by the Canadian Pediatric Society ${ }^{(22)}$.

\section{Vitamin D-containing supplements and/or analogue use}

During the household visit, participants were asked to name all prescription medications and over-the-counter and herbal remedies taken in the past month. At the MEC interview, participants were asked whether they were still taking any medications or remedies they listed at the time of the household interview, and the names of any new ones they started taking since the household interview were collected. An Anatomical Therapeutic Chemical (ATC) classification code was assigned to each medication recorded using the drug identification number (DIN). For the present study, online ATC/defined daily dose system was used to create the variable 'vitamin D-containing supplement and/or analogue use'. Those who recorded one or more of A11CC (vitamin D and analogues), A11CC01 (ergocalciferol or vitamin $\mathrm{D}_{2}$ ), A11CC02 (dihydrotachysterol or synthetic vitamin D analogue), A11CC03 (alfacalcidol or analogue of vitamin D), A11CC04 (calcitriol) and A11CC05 (cholecalciferol or vitamin $\mathrm{D}_{3}$ ) codes were collectively grouped as 'vitamin D supplement users'. Only individuals who reported taking the supplements during the past 1 month were considered when calculating vitamin D-containing supplement and/or analogue use in this study. When an individual used a medication that was not assigned an ATC code due to missing or not existent DIN, they were grouped as 'not stated'. The rest of the respondents were considered 'non-users'.

\section{Vitamin D-rich foods}

Food frequency data were collected as part of the household questionnaire. We considered the frequency of consumption of fish (excluding shell fish), vitamin D-fortified cows' milk (milk or flavoured milk beverages or use along with cereal), vitamin D-fortified margarine, eggs (eggs or egg dishes that include the yolk such as eggs, omelette, frittata or quiche excluding all egg dishes made with only egg whites), red meat (beef, hamburger, pork or lamb) and liver (included all types of liver such as beef, veal, pork or chicken but excluding liverwurst and liver pâté) within the previous month in the present study.

\section{Other covariates}

In addition to vitamin D-containing supplement and/or analogue use, sex, age, household income, body weight status, ethnicity and season were considered as determinants of vitamin D deficiency, sufficiency and serum concentration. Only $77 \%$ of respondents aged 3-79 years provided household income, and therefore income imputed by Statistics Canada was used to create three categories of $\leq \$ 50000, \$ 51000-100000$ and $\geq \$ 101000$ on the basis of imputation procedures found in the CHMS Data User Guide for Cycle $3^{(26)}$. Participants' standing height was measured to the nearest $0.01 \mathrm{~mm}$ using a fixed stadiometer (QuickMedical 235A) and body weight to the nearest $0.01 \mathrm{~kg}$ using a digital scale (Mettler Toledo 2256 VLC). BMI was calculated as weight by height squared $\left(\mathrm{kg} / \mathrm{m}^{2}\right)$. Body weight status was defined using BMI as 'underweight', 'normal weight', 'overweight' and 'obese', based on the WHO classification for children and adolescents ${ }^{(29)}$. 'Underweight' and 'normal weight' categories were combined into a single category because of the small number of underweight children. Ethnicity was dichotomised as 'white' and 'non-white' (i.e., Chinese, South Asian, Black, Filipino, Latin American, Southeast Asian, Arab, West Asian, Japanese, Korean, Aboriginal and other ethnic backgrounds) on the basis of responses to the household questionnaire. Ethnicity served as a proxy for skin colour and the capacity to cutaneously synthesise vitamin $\mathrm{D}^{(13)}$. Season was categorised as 'winter' (December of the previous year, January, February), 'spring' (March, April, May), 'summer' (June, July, August) and 'fall' (September, October, November) ${ }^{(30)}$ on the basis of the date of the visit to MEC to provide blood samples.

\section{Statistical analyses}

All analyses were weighted to represent national estimates of individuals aged 3-18 years in Canada and to accommodate the complex sampling design. Bootstrap weights were provided with the CHMS data. Descriptive statistics were presented as means with bootstrap standard errors and as percentage of children achieving $<30 \mathrm{nmol} / \mathrm{l}$ and percentage of children achieving 40, 50 and $75 \mathrm{nmol} / \mathrm{l}$. The associations of sex, age, household income, body weight status, ethnicity, season, food frequency (frequency of consuming fish, cows' milk, margarine, egg and red meat) and vitamin D-containing supplement and/ or analogue use with vitamin D deficiency $(<30 \mathrm{nmol} / \mathrm{l})$ and sufficiency $(\geq 50 \mathrm{nmol} / \mathrm{l})$ were determined using multiple logistic regression. Geographic location was not significantly associated with either vitamin D deficiency or sufficiency and was excluded from the regression analyses to preserve df. The association of the above-listed factors with serum 25(OH)D concentration was investigated with multiple linear regression. The associations of vitamin D sufficiency based on the cut-off of $50 \mathrm{nmol} / 1$, deficiency based on the cut-off of $30 \mathrm{nmol} / \mathrm{l}$ and the serum $25(\mathrm{OH}) \mathrm{D}$ concentration, respectively, on frequency of consuming vitamin D-rich foods (fish, cows' milk, margarine, egg and red meat) were adjusted for age, household income, season, BMI, ethnicity and vitamin D-containing supplements and/or analogue use. Liver was not included in any analysis, and milk, fish, egg, red meat and margarine consumption was grouped into two categories in the regression models because of their low frequency in the diet. To avoid small cell sizes and to preserve df, age and BMI were considered as continuous variables when dietary data were included in the 
multivariable models. As the present study is a secondary analysis of data from a national survey, the sample size was not powered to find out whether there were differences between groups of children for vitamin D deficiency and sufficiency. All analyses were carried out using Stata, version $14 \cdot 0$ (StataCorp LP). Statistical significance was defined as a $P$ value $<0.05$. The Health Research Ethics Board of the University of Alberta and Statistics Canada approved this study. All processes of CHMS were reviewed and approved by the Health Canada and Public Health Agency of Canada Research Ethics Board.

\section{Results}

The mean serum 25(OH)D concentration of Canadian children in 2012/2013 was $62 \cdot 2 \mathrm{nmol} / 1$ (95\% CI 55.8, 68.7; bootstrap SE 3.0) and the median was $62 \cdot 0 \mathrm{nmol} / 1$ (interquartile range $47 \cdot 6-74 \cdot 5$ ). The percentage of children with serum vitamin $\mathrm{D}$ concentrations $>30 \mathrm{nmol} / \mathrm{l}$ was $5 \cdot 6 \%$ (Table 1 ). The percentage of children with sufficient serum vitamin D concentrations based on the $50 \mathrm{nmol} / \mathrm{l}$

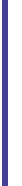
cut-off was $70.9 \%$ and based on the $75 \mathrm{nmol} / \mathrm{l}$ cut-off $23.5 \%$ (Table 1). The mean serum 25(OH)D concentrations of children aged $3-7,8-12$ and $13-18$ years were $66.9 \mathrm{nmol} / 1$ (95\% CI 60.2, 73.6; bootstrap SE $3 \cdot 2), 63 \cdot 1 \mathrm{nmol} / 1$ (95\% CI 56.2, 70.1; bootstrap SE 3.3 ) and $58.3 \mathrm{nmol} / 1$ (95\% CI 52.0, 64.7; bootstrap SE 3.0), respectively. Only $9.2 \%$ of children reportedly took vitamin D supplements and/or analogues (Table 2). The most commonly consumed vitamin D-rich food was milk, with $77.2 \%$ reporting drinking milk once a day or more frequently (Table 2). The prevalence of at least weekly consumption of milk, red meat, eggs, margarine, fish and liver was 93.0, 86.5, 72.6, 47.4, 14.4 and $1 \cdot 1 \%$, respectively (Table 2 ).

Table 3 depicts the associations of socio-demographic factors, anthropometric factors, season and vitamin D-containing supplements and/or analogue use with the likelihood of meeting vitamin D deficiency and sufficiency (multiple logistic regression model) and serum 25(OH)D concentrations (multiple linear regression model). Older children (13-18 years old) were less likely to have sufficient vitamin D concentrations (meeting $50 \mathrm{nmol} / \mathrm{l}:$ OR $0.3 ; 95 \%$ CI $0.2,0.5)$ compared with younger children (3-7 year old). Household income was positively associated with meeting the sufficiency threshold of $50 \mathrm{nmol} / 1$ serum 25(OH)D. Obese children compared with underweight/ normal-weight children combined were less likely to meet the sufficiency threshold (OR 0.4; $95 \%$ CI 0.2, 0.8), as were children of non-white ethnicity compared with white ethnicity (OR 0.3; $95 \%$ CI $0.2,0.6)$. Age, non-white ethnicity and being overweight or obese were negatively associated with serum 25(OH)D concentrations, whereas household income was positively associated with it. Children were more likely to have higher serum $25(\mathrm{OH}) \mathrm{D}$ concentrations during summer and fall than in winter.

Table 1. General characteristics of Canadian children participating in the 2012/2013 Canadian Health Measures Survey

\begin{tabular}{|c|c|c|c|c|c|}
\hline Characteristics & $\begin{array}{l}\text { Weighted percentage } \\
\text { ( } n \text { 2270) }\end{array}$ & $\begin{array}{c}\text { Deficient } \\
(\% ;<30 \mathrm{nmol} / \mathrm{l}) \dagger\end{array}$ & $\begin{array}{l}\text { Meeting median requirement } \\
(\% ; \geq 40 \mathrm{nmol} / \mathrm{l}) \dagger\end{array}$ & $\begin{array}{c}\text { Sufficient } \\
(\% ; \geq 50 \mathrm{nmol} / \mathrm{l}) \dagger\end{array}$ & $\begin{array}{c}\text { Sufficient } \\
(\% ; \geq 75 \mathrm{nmol} / \mathrm{l}) \ddagger\end{array}$ \\
\hline All children & $100 \cdot 0$ & $5 \cdot 6$ & $86 \cdot 1$ & $70 \cdot 9$ & 23.5 \\
\hline \multicolumn{6}{|l|}{ Age } \\
\hline $3-7$ years & $29 \cdot 1$ & $3 \cdot 3^{\star}$ & $92 \cdot 6^{\star \star \star}$ & $80 \cdot 2^{\star \star \star}$ & $28 \cdot 5^{*}$ \\
\hline $8-12$ years & 29.8 & 3.2 & 91.0 & 74.2 & 23.5 \\
\hline $13-18$ years & $41 \cdot 1$ & $9 \cdot 0$ & $77 \cdot 9$ & $62 \cdot 0$ & $20 \cdot 0$ \\
\hline \multicolumn{6}{|l|}{ Sex } \\
\hline Boys & 51.6 & $6 \cdot 8$ & 84.8 & 71.6 & 23.1 \\
\hline Girls & 48.4 & $4 \cdot 3$ & 87.4 & $70 \cdot 2$ & 23.9 \\
\hline \multicolumn{6}{|l|}{ Household income } \\
\hline$\leq \$ 50000$ & 28.5 & $11 \cdot 3^{\star \star}$ & $76 \cdot 8^{\star \star \star}$ & $55 \cdot 8^{\star \star \star}$ & $16 \cdot 1^{*}$ \\
\hline$\$ 51000-100000$ & $36 \cdot 1$ & $4 \cdot 1$ & 85.5 & 70.4 & $23 \cdot 7$ \\
\hline$\geq \$ 101000$ & 35.4 & 2.6 & $94 \cdot 1$ & 83.6 & $29 \cdot 3$ \\
\hline \multicolumn{6}{|l|}{ Region of residence } \\
\hline Atlantic & $6 \cdot 2$ & $<1.0$ & $90 \cdot 8$ & 78.5 & $22 \cdot 7$ \\
\hline Quebec & 21.9 & $9 \cdot 0$ & $78 \cdot 2$ & 67.4 & $24 \cdot 3$ \\
\hline Ontario & $40 \cdot 0$ & $4 \cdot 3$ & 88.3 & 71.1 & 20.9 \\
\hline The Prairies & $19 \cdot 4$ & $5 \cdot 6$ & 89.1 & $76 \cdot 7$ & $30 \cdot 3$ \\
\hline British Columbia & 12.5 & $4 \cdot 6$ & $85 \cdot 8$ & 63.7 & $20 \cdot 1$ \\
\hline \multicolumn{6}{|l|}{ Ethnicity } \\
\hline White & 63.5 & $2 \cdot 8^{\star \star \star}$ & $91 \cdot 5^{\star \star \star}$ & $78 \cdot 6^{\star \star \star}$ & $30 \cdot 2^{\star \star \star}$ \\
\hline Non-white§ & 36.5 & 10.5 & $76 \cdot 7$ & 57.6 & 11.8 \\
\hline \multicolumn{6}{|l|}{ Body weight status } \\
\hline Underweight & 4.9 & $6 \cdot 8$ & $91 \cdot 7^{\star \star \star}$ & $87 \cdot 5^{\star \star \star}$ & $27 \cdot 1^{*}$ \\
\hline Normal weight & 68.8 & 4.8 & 88.8 & $75 \cdot 2$ & $25 \cdot 3$ \\
\hline Overweight & 14.7 & 6.9 & 85.0 & 61.0 & 23.6 \\
\hline Obese & $11 \cdot 6$ & $8 \cdot 1$ & & $51 \cdot 1$ & 11.5 \\
\hline \multicolumn{6}{|l|}{ Season } \\
\hline Winter & $20 \cdot 6$ & $14 \cdot 6^{\star \star \star}$ & $66 \cdot 0^{\star \star \star}$ & $50 \cdot 5^{\star \star \star}$ & $12 \cdot 3^{\star \star \star}$ \\
\hline Spring & 30.4 & 3.8 & $88 \cdot 1$ & 67.3 & $12 \cdot 9$ \\
\hline Summer & $25 \cdot 2$ & 3.2 & 92.6 & $78 \cdot 8$ & 31.0 \\
\hline Fall & 23.8 & $2 \cdot 7$ & 93.8 & $84 \cdot 8$ & 38.8 \\
\hline
\end{tabular}

$\chi^{2}$ Test to determine the difference between frequencies within each characteristic: ${ }^{*} P<0.05,{ }^{* \star} P<0.01,{ }^{* \star *} P<0.001$.

$\dagger$ Based on the definition of the Institute of Medicine ${ }^{(20)}$.

$\mp$ Based on the definition of the Canadian Pediatric Society ${ }^{(22)}$

$\S$ Non-white ethnicity included non-European and minority groups. 
Table 2. Vitamin D status and intake of vitamin D-rich sources reported by Canadian children participating in the 2012/2013 Canadian Health Measures Survey

\begin{tabular}{|c|c|c|c|c|c|}
\hline & $\begin{array}{l}\text { Weighted percentage } \\
\qquad(n 2270)\end{array}$ & $\begin{array}{c}\text { Deficient } \\
(\% ;<30 \mathrm{nmol} / \mathrm{l}) \dagger\end{array}$ & $\begin{array}{l}\text { Meeting median requirement } \\
\qquad(\% ; \geq 40 \mathrm{nmol} / \mathrm{l}) \dagger\end{array}$ & $\begin{array}{c}\text { Sufficient } \\
(\% ; \geq 50 \mathrm{nmol} / \mathrm{l}) \dagger\end{array}$ & $\begin{array}{c}\text { Sufficient } \\
(\% ; \geq 75 \mathrm{nmol} / \mathrm{l}) \ddagger\end{array}$ \\
\hline \multicolumn{6}{|c|}{ Vitamin D-containing supplement and/or analogue use in the previous month } \\
\hline Users & 9.2 & $5 \cdot 6$ & 84.4 & 70.5 & 23.2 \\
\hline Non-users & $74 \cdot 7$ & 9.9 & $85 \cdot 7$ & $72 \cdot 6$ & 24.9 \\
\hline Not stated & $16 \cdot 1$ & $3 \cdot 2$ & 88.6 & $72 \cdot 0$ & $24 \cdot 2$ \\
\hline \multicolumn{6}{|c|}{ Natural vitamin D sources } \\
\hline \multicolumn{6}{|c|}{ Fish } \\
\hline$\leq 1$ time/week & $85 \cdot 6$ & 5.9 & $85 \cdot 8$ & 71.0 & 22.9 \\
\hline $1-6$ times/week & 14.4 & 3.9 & 87.9 & $70 \cdot 6$ & $26 \cdot 8$ \\
\hline$\geq 7$ times/week & 0.0 & NA & NA & NA & NA \\
\hline \multicolumn{6}{|l|}{ Eggs } \\
\hline$\leq 1$ time/week & $27 \cdot 4$ & $7 \cdot 2$ & $85 \cdot 2$ & $70 \cdot 3$ & 21.9 \\
\hline$\overline{1}-6$ times/week & 66.9 & 4.7 & $86 \cdot 1$ & $70 \cdot 6$ & 24.5 \\
\hline$\geq 7$ times/week & $5 \cdot 7$ & 7.9 & $90 \cdot 4$ & $77 \cdot 7$ & 19.5 \\
\hline \multicolumn{6}{|l|}{ Red meat } \\
\hline$\leq 1$ time/week & 13.5 & $10 \cdot 4$ & 80.5 & 65.5 & $17 \cdot 9$ \\
\hline 1-6 times/week & 78.9 & 4.7 & $86 \cdot 8$ & 71.9 & $24 \cdot 1$ \\
\hline$\geq 7$ times/week & 7.6 & $6 \cdot 4$ & $88 \cdot 2$ & $70 \cdot 3$ & $27 \cdot 4$ \\
\hline \multicolumn{6}{|l|}{ Liver } \\
\hline$\leq 1$ time/week & 98.9 & 5.5 & $86 \cdot 1$ & $71 \cdot 1$ & 23.6 \\
\hline$>1$ times/week & $1 \cdot 1$ & $10 \cdot 6$ & 80.5 & $59 \cdot 3$ & 11.8 \\
\hline \multicolumn{6}{|c|}{ Fortified vitamin D sources§ } \\
\hline \multicolumn{6}{|l|}{ Milk } \\
\hline$\leq 1$ time/week & $7 \cdot 0$ & $12 \cdot 3^{*}$ & $66 \cdot 2^{\star \star}$ & $52 \cdot 3^{\star \star}$ & $26 \cdot 0$ \\
\hline 1-6 times/week & $15 \cdot 8$ & $8 \cdot 3$ & 78.9 & $59 \cdot 0$ & 19.9 \\
\hline$\geq 7$ times/week & $77 \cdot 2$ & 4.4 & 89.4 & $75 \cdot 1$ & 24.0 \\
\hline \multicolumn{6}{|l|}{ Margarine } \\
\hline$\leq 1$ time/week & $52 \cdot 6$ & 7.4 & $85 \cdot 0$ & $69 \cdot 3$ & 21.4 \\
\hline 1-6 times/week & $27 \cdot 6$ & 3.7 & $85 \cdot 1$ & $72 \cdot 6$ & $24 \cdot 1$ \\
\hline$\geq 7$ times/week & $19 \cdot 8$ & 3.5 & $90 \cdot 2$ & 72.9 & $28 \cdot 3$ \\
\hline
\end{tabular}

The association of vitamin D-containing supplement and/or analogue use on achieving vitamin D sufficiency was not statistically significant, but it was positively associated with serum $25(\mathrm{OH}) \mathrm{D}$ concentrations $(\beta 5.9 \mathrm{nmol} / \mathrm{l} ; 95 \% \mathrm{CI} 1 \cdot 3,12 \cdot 1 \mathrm{nmol} / \mathrm{l})$. Comparable with the factors associated with meeting vitamin $D$ sufficiency based on the cut-off of $50 \mathrm{nmol} / 1$, household income, age, body weight status, season and ethnicity were associated with meeting the median vitamin $\mathrm{D}$ requirement of $40 \mathrm{nmol} / \mathrm{l}$, and therefore the results are not shown in Table 3.

Children who consumed cows' milk once a day or more frequently were more likely to achieve vitamin D sufficiency ( $\geq 50 \mathrm{nmol} / \mathrm{l}$ ) compared with those who consumed it less frequently (OR 2.4; 95\% CI 1.7, 3.3) (Table 4). Other dietary factors were not associated with meeting sufficiency in a statistically significant manner. Higher serum 25(OH)D concentrations were found among children who consumed fish more than once a week compared with those who consumed fish once a week or less frequently, and among children who consumed margarine more than once a week compared with those who consumed it once a week or less frequently (Table 4). In addition, consumption of both milk once a day or more frequently compared with less than once a week (OR 2.8; $95 \%$ CI 1.4, 5.6) and margarine more than once a week compared with once a week or less frequently (OR 1.5; $95 \%$ CI $1 \cdot 0,2 \cdot 2)$ were positively associated with meeting the median requirement $(\geq 40 \mathrm{nmol} / \mathrm{l})$ (the results are not shown in Table 4).

\section{Discussion}

We used nationally representative data collected in 2012 and 2013 to assess whether Canadian children, aged 3-18 years, have sufficient serum $25(\mathrm{OH}) \mathrm{D}$ concentrations and to study the determinants of vitamin D sufficiency and serum 25(OH)D concentrations following the 2010 revision of the RDA for vitamin D from 5 to $15 \mu \mathrm{g} / \mathrm{d}$. We observed that $71 \%$ of children had sufficient serum vitamin $\mathrm{D}$ concentrations based on the $50 \mathrm{nmol} / \mathrm{l}$ cut-off. Fewer children (23\%) met the cut-off for vitamin $\mathrm{D}$ adequacy of $75 \mathrm{nmol} / 1$ recommended by the Canadian Pediatric Society ${ }^{(22)}$. A study by Whiting et al. $^{(13)}$ based on data collected in 2007-2009 revealed that Canadians aged 6-79 years were more likely to be vitamin $\mathrm{D}$ insufficient if they were male, were non-white, did not supplement and when examined during winter. In 2010/2011, 88\% of pre-schoolers (2-5 years) attending daycare in the province of Montréal had vitamin D sufficiency ${ }^{(31)}$. In the present study, focusing on children and considering a wider range of potential determinants, we observed that supplement use and sex were not contributing to vitamin D sufficiency. However, we did observe that increasing age, lower household income, obesity, non-white ethnicity, the winter season and infrequent 
Table 3. Associations of age, sex, household income, BMl status, season, ethnicity and vitamin D-containing supplements and/or analogue use with the likelihood of achieving vitamin $\mathrm{D}$ sufficiency and with serum 25 -hydroxy vitamin $\mathrm{D}(25(\mathrm{OH}) \mathrm{D})$ concentrations among Canadian children, participating in the 2012/2013 Canadian Health Measures Survey

(Odds ratios, $\beta$-coefficients and $95 \%$ confidence intervals)

\begin{tabular}{|c|c|c|c|c|c|c|}
\hline \multirow[b]{2}{*}{ Covariate } & \multicolumn{2}{|c|}{$\begin{array}{l}\text { Vitamin D deficiency } \\
\qquad(<30 \mathrm{nmol} / /) \dagger \ddagger \S\end{array}$} & \multicolumn{2}{|c|}{$\begin{array}{l}\text { Vitamin D sufficiency } \\
\qquad(\geq 50 \mathrm{nmol} / \mathrm{l}) \dagger \ddagger \S\end{array}$} & \multicolumn{2}{|c|}{$\begin{array}{l}\text { Serum } 25(\mathrm{OH}) \mathrm{D} \\
\text { concentration†‡ }\end{array}$} \\
\hline & OR & $95 \% \mathrm{Cl}$ & OR & $95 \% \mathrm{Cl}$ & $\beta$ & $95 \% \mathrm{Cl}$ \\
\hline Intercept & & & & & $57 \cdot 5^{\star \star \star}$ & $49 \cdot 8,65 \cdot 6$ \\
\hline \multicolumn{7}{|l|}{ Age } \\
\hline $3-7$ years & Ref. & & Ref. & & Ref. & \\
\hline $8-12$ years & 0.8 & $0 \cdot 1,4 \cdot 3$ & 0.6 & $0.3,1 \cdot 1$ & $-4 \cdot 1^{*}$ & $-7 \cdot 6,-0 \cdot 6$ \\
\hline $13-18$ years & 0.2 & $0.0,1.3$ & $0.3^{\star \star \star}$ & $0.2,0.5$ & $-8 \cdot 6^{\star \star \star}$ & $-10 \cdot 4,-6 \cdot 9$ \\
\hline \multicolumn{7}{|l|}{ Sex } \\
\hline Boys & Ref. & & Ref. & & Ref. & \\
\hline Girls & 1.4 & $0.5,4.0$ & 0.8 & $0.6,1 \cdot 1$ & 0.0 & $-1.4,1.4$ \\
\hline \multicolumn{7}{|l|}{ Household income } \\
\hline$\leq \$ 50000$ & Ref. & & Ref. & & Ref. & \\
\hline$\$ 50001-100000$ & $2 \cdot 6$ & $0.9,7 \cdot 1$ & $1.8^{*}$ & $1 \cdot 1,2 \cdot 9$ & $5 \cdot 1^{*}$ & $0.9,9.2$ \\
\hline$\geq \$ 100001$ & $2 \cdot 9$ & $0.9,9.7$ & $3 \cdot 2^{\star \star \star}$ & $1.9,5.3$ & $9 \cdot 1^{\star \star \star}$ & $4 \cdot 6,13 \cdot 7$ \\
\hline \multicolumn{7}{|l|}{ Ethnicity } \\
\hline White & Ref. & & Ref. & & Ref. & \\
\hline Non-white & 0.2 & $0.1,0.6$ & $0 \cdot 3^{\star \star}$ & $0.2,0.6$ & $-11 \cdot 3^{\star \star \star}$ & $-16 \cdot 0,-6 \cdot 6$ \\
\hline \multicolumn{7}{|l|}{ Body weight status } \\
\hline Underweight/normal weight & Ref. & & Ref. & & Ref. & \\
\hline Overweight & 1.2 & $0.4,3.3$ & 0.6 & $0.3,1.2$ & $-1 \cdot 3$ & $-5 \cdot 2,2 \cdot 6$ \\
\hline Obese & 1.4 & $0 \cdot 2,9 \cdot 3$ & $0.4^{*}$ & $0.2,0.8$ & $-8 \cdot 0^{* \star *}$ & $-11 \cdot 0,-5 \cdot 0$ \\
\hline \multicolumn{7}{|l|}{ Season } \\
\hline Winter & Ref. & & Ref. & & Ref. & \\
\hline Spring & 3.7 & $0.7,18.5$ & 1.9 & $0.7,5 \cdot 2$ & $3 \cdot 0$ & $-6 \cdot 0,12 \cdot 0$ \\
\hline Summer & $6 \cdot 7^{*}$ & $1 \cdot 0,43 \cdot 4$ & $5 \cdot 5^{\star *}$ & $2 \cdot 1,14 \cdot 3$ & $15 \cdot 9^{\star \star *}$ & $8 \cdot 1,23 \cdot 7$ \\
\hline Fall & $4 \cdot 1$ & $0.9,19.8$ & $5 \cdot 2^{\star *}$ & $2 \cdot 2,12 \cdot 3$ & $15 \cdot 2^{\star *}$ & $4 \cdot 2,26 \cdot 3$ \\
\hline \multicolumn{7}{|c|}{ Vitamin D-containing supplement and/or analogue use } \\
\hline Non-users & Ref. & & Ref. & & Ref. & \\
\hline Users & 1.0 & $0.2,4.8$ & 1.6 & $0.5,5.9$ & $5 \cdot 9^{*}$ & $1 \cdot 3,12 \cdot 1$ \\
\hline Not stated & 1.8 & $0.5,6.5$ & 1.0 & $0.5,1.7$ & 2.5 & $-0.4,5.5$ \\
\hline
\end{tabular}

Ref., referent values.

${ }^{\star} P<0.05,{ }^{\star \star} P \leq 0.01,{ }^{\star * \star} P \leq 0.001$.

† Results of 2270 participants aged 3-18 years were weighted to represent national estimates and adjusted for all covariates in the table.

$\ddagger$ Adjusted for all other covariates in the table.

$\S$ Based on the definition of the Institute of Medicine ${ }^{(20)}$.

Table 4. Associations of vitamin D-rich foods with vitamin D sufficiency and serum 25-hydroxy vitamin D (25(OH)D) concentration, respectively, among Canadian children, participating in the 2012/2013 Canadian Health Measures Survey (Odds ratios, $\beta$-coefficients and $95 \%$ confidence intervals)

\begin{tabular}{|c|c|c|c|c|c|c|}
\hline \multirow[b]{2}{*}{ Covariate } & \multicolumn{2}{|c|}{$\begin{array}{l}\text { Vitamin D deficiency } \\
(<30 \mathrm{nmol} / \mathrm{l}) \dagger \ddagger \S\end{array}$} & \multicolumn{2}{|c|}{$\begin{array}{l}\text { Vitamin D sufficiency } \\
\quad(\geq 50 \mathrm{nmol} / \mathrm{l}) \dagger \ddagger \S\end{array}$} & \multicolumn{2}{|c|}{$\begin{array}{l}\text { Serum } 25(\mathrm{OH}) \mathrm{D} \\
\text { concentration† }\end{array}$} \\
\hline & OR & $95 \% \mathrm{Cl}$ & OR & $95 \% \mathrm{Cl}$ & $\beta$ & $95 \% \mathrm{Cl}$ \\
\hline \multicolumn{7}{|l|}{ Milk } \\
\hline $\begin{array}{l}<7 \text { time/week } \\
\geq 7 \text { times/week }\end{array}$ & $\begin{array}{l}\text { Ref. } \\
1.6\end{array}$ & $0.5,4.9$ & $\begin{array}{l}\text { Ref. } \\
2 \cdot 4^{\star *}\end{array}$ & $1 \cdot 7,3 \cdot 3$ & $\begin{array}{l}\text { Ref. } \\
4 \cdot 4^{* *}\end{array}$ & $1.5,7 \cdot 4$ \\
\hline $\begin{array}{l}\text { Eggs } \\
<1 \text { time/week }\end{array}$ & & & & & & \\
\hline $\begin{array}{l}\leq 1 \text { time/week } \\
>1 \text { time/week }\end{array}$ & $\begin{array}{l}\text { Ref. } \\
1.4\end{array}$ & $0.4,4.9$ & $\begin{array}{l}\text { Ref. } \\
1.2\end{array}$ & $0.7,1 \cdot 8$ & $\begin{array}{l}\text { Ref. } \\
1.9\end{array}$ & $-0.8,4.7$ \\
\hline $\begin{array}{l}\text { Fish } \\
\leq 1 \text { time/week }\end{array}$ & & & & & & \\
\hline $\begin{array}{l}\leq 1 \text { time/week } \\
>1 \text { times/week }\end{array}$ & $\begin{array}{l}\text { Ref. } \\
2 \cdot 2\end{array}$ & $0.4,11 \cdot 1$ & $\begin{array}{l}\text { Ref. } \\
1.2\end{array}$ & $0 \cdot 8,1 \cdot 8$ & $\begin{array}{l}\text { Ref. } \\
4 \cdot 2^{*}\end{array}$ & $0.2,8 \cdot 3$ \\
\hline $\begin{array}{l}\text { Red meat } \\
\leq 1 \text { time/week }\end{array}$ & & & & & & \\
\hline $\begin{array}{l}\leq 1 \text { time/week } \\
>1 \text { time/week }\end{array}$ & $\begin{array}{l}\text { Ret. } \\
1.5\end{array}$ & $0.3,8 \cdot 1$ & $\begin{array}{l}\text { Ret. } \\
1.0\end{array}$ & $0.5,1.9$ & $\begin{array}{l}\text { Ret. } \\
-0.4\end{array}$ & $-5 \cdot 1,4 \cdot 4$ \\
\hline $\begin{array}{l}\text { Margarine } \\
<1 \text { time/week }\end{array}$ & & & & & & \\
\hline$>1$ time/week & $2 \cdot 8^{*}$ & $1.0,7.9$ & 1.3 & $0.9,1.9$ & $\begin{array}{l}\text { Rel. } \\
2 \cdot 8^{*}\end{array}$ & $0.3,5 \cdot 4$ \\
\hline
\end{tabular}

Ref., referent values.

${ }^{\star} P \leq 0.05,{ }^{*} P<0.001$.

† Results of 2270 participants aged 3-18 years were weighted to represent national estimates and adjusted for all covariates in the table. $\ddagger$ Adjusted for age, household income, BMI, season, ethnicity and all other dietary variables in the table.

$\S$ Based on the definition of the Institute of Medicine ${ }^{(20)}$. 
milk consumption were associated with vitamin D insufficiency in children aged 3-18 years.

The RDA for vitamin $\mathrm{D}$ is based on the assumption of minimal sun exposure; therefore, in Canada supplements, mandatorily fortified foods such as cows' milk and margarine, and natural vitamin D sources such as red meat, liver, fatty fish and egg yolks must provide nutrient adequacy in the absence of cutaneous synthesis. Our findings suggest that current food choices and supplement use are insufficient to ensure that all children maintain $25(\mathrm{OH}) \mathrm{D}$ concentrations of $50 \mathrm{nmol} / 1$. Similar to previous CHMS surveys in 2007-2009 ${ }^{(13)}$ and 2009-2011 $1^{(12)}$, the most commonly consumed vitamin D-rich food source among children in the CHMS 2012/2013 was milk. Its frequent consumption was associated with a greater likelihood of achieving sufficiency, potentially attributable to both mandatory vitamin $\mathrm{D}$ fortification and the formal recommendations for daily milk consumption included in the Federal Government document, Eating Well with Canada's Food Guide ${ }^{(32)}$. Similar to Canadian children, the highest dietary contributor of vitamin D among British children is milk and milk products $^{(6)}$, despite the fact that only margarine and infant formula are mandatory fortified in the $\mathrm{UK}^{(6)}$. This could be due to low consumption of margarine by children and the promotion of milk and milk products by Public Health England in The Eatwell Guide $e^{(33)}$

Some may argue that achieving appropriate $25(\mathrm{OH}) \mathrm{D}$ concentrations through use of vitamin D supplements is more practical than through the diet for the following reasons - a higher requirement of vitamin $\mathrm{D}$ in obese children ${ }^{(2,4,34,35)}$, lactose-intolerance limits milk consumption in some children ${ }^{(6,36)}$, the cost of some natural food items rich in vitamin D may be high ${ }^{(37,38)}$ and limited availability and accessibility of vitamin D-rich foods ${ }^{(39)}$. The formal recommendations for vitamin D supplement use in Canada are only for infants and those above the age of 50 years ${ }^{(4)}$. This explains the J-shaped curve of vitamin D-containing supplement use by age ${ }^{(40)}$. The present study further revealed higher serum 25(OH)D concentrations in summer and fall compared with spring and winter, reflecting that cutaneous synthesis is higher during summer months ${ }^{(41)}$ due to Canada's high latitude. Therefore, formal recommendations for vitamin D supplement use for children are likely to increase their use, and consequently benefit vitamin D status and bone health mostly during winter and spring months.

We identified that the use of vitamin D-containing supplements and/or analogues was positively associated with serum 25(OH)D concentration. However, the difference between children reportedly using $v$. not using supplements and/ or analogues was relatively small $(6.9 \mathrm{nmol} / \mathrm{l})$. Those who reported using supplements may not have been taking them regularly, and the amount of vitamin D present in the supplements and/or analogues may not have been enough to make a big difference. Unfortunately, we were unable to explore these reasons as the data on frequency of vitamin D-containing supplement and/or analogue use and the amount of vitamin D in the supplements and/or analogues were not available.

At present, there is a debate that the revised DRI for vitamin D is underestimated $^{(22,42-44)}$ or overestimated ${ }^{(45)}$. The Canadian
Endocrine Society ${ }^{(46)}$, the Canadian Pediatric Society ${ }^{(22)}$ and the Canadian Dermatology Association ${ }^{(17)}$ recommend higher intakes of vitamin D for children than that recommended by the DRI to assure sufficiency. There is evidence that the current DRI of $15 \mu \mathrm{g}$ may not be high enough to raise serum concentrations to at least $50 \mathrm{nmol} / 1$, particularly if sun exposure is limited. For example, Hall et al. ${ }^{(47)}$ estimated that individuals of African ancestry with low sun exposure who live in California need $16.25 \mu \mathrm{g}$ (in summer months) to $42.50 \mu \mathrm{g}$ (in winter months) of vitamin $\mathrm{D}$ to achieve serum $25(\mathrm{OH}) \mathrm{D}$ concentrations of $50 \mathrm{nmol} / \mathrm{l}$ or more. This raises the question as to why the same DRI for vitamin D is established for citizens living in both Canada and the USA considering that Canadians have fewer fortified food choices than Americans and opportunities for cutaneous synthesis of vitamin D due to Canada's higher latitude. The most recent report of the Scientific Advisory Committee on Nutrition in the $\mathrm{UK}^{(19)}$ recommends $10 \mu \mathrm{g}$ of vitamin D daily for citizens of the UK at age 4 years and above, who similar to Canadian citizens live at high latitudes. The recommendation assumes minimal sun exposure. It is important to consider whether citizens are able to achieve $10 \mu \mathrm{g}$ of vitamin D daily from food sources alone, and whether that amount is high enough to assure vitamin D sufficiency.

In our study, obese children had lower serum 25(OH)D concentrations and were less likely to be vitamin D sufficient based on the $50 \mathrm{nmol} / \mathrm{l}$ cut-off, indicating that they are not consuming the extra vitamin $\mathrm{D}$ that has been identified to be necessary for obese individuals to achieve vitamin $\mathrm{D}$ sufficiency ${ }^{(34,35)}$. Previous studies have suggested that the daily vitamin $\mathrm{D}$ intake for overweight and obese adults should be 1.5 times and 2-3 times higher relative to normal-weight individuals, respectively ${ }^{(34,35)}$, indicating the essentiality of supplements for those with excess body weights. The authors further suggested reconsideration of the DRI serum cut-off values ${ }^{(34,42)}$ and providing body weight-specific cut-offs ${ }^{(34)}$. Moreover, the Endocrine Society of Canada recommends obese children and adults take at least 2-3 times more vitamin D than that recommended for their age group ${ }^{(46)}$, and the Canadian Pediatric Society $^{(22)}$ suggests body weight- and BMI-specific vitamin D requirements when establishing dietary requirements. On the basis of our findings, there is either a lack of awareness of the differential needs, or obese children are unable to access enough dietary vitamin $\mathrm{D}$ to achieve their increased requirement, or a combination of both. Furthermore, nearly $37 \%$ of children in the present study were non-white and at increased risk for lower serum concentrations and insufficiency. Deeply pigmented skin requires a longer period of sun exposure to synthesise vitamin $D$ or a larger area of bare skin to be exposed to UV-B radiation ${ }^{(47)}$. Therefore, the use of supplements also could help ensure vitamin D sufficiency in children of non-white ethnicity.

This study has certain limitations. We could not calculate dietary vitamin D intake, as data on the dose and frequency of intake of supplements and the amounts of food consumed were not collected. The possible misclassification of supplements or medications that contain vitamin D may have resulted in underestimation or overestimation of their use. The low prevalence of supplement users in our study resulted in a lack of statistical power to detect associations. The differences in 
serum 25(OH)D concentrations between supplement users and non-users indicate that the data processing method used to identify vitamin D supplement use was reasonably valid. Strengths of our study include that the CHMS followed quality control measures to maintain data quality, including for interviews, biological specimen collection and analysis. Complete and accurate data were ensured by performing data validation halfway through and at the end of data collection. Cycle 3 CHMS interview and laboratory data were compared with cycle 1 and 2, Canadian Community Health Survey, and US National Health and Nutrition Examination Survey to ensure that the data were consistent among these different data sources ${ }^{(27)}$.

\section{Conclusions}

The percentage of children with serum vitamin $\mathrm{D}$ concentrations $<30 \mathrm{nmol} / \mathrm{l}$ was $5.6 \%$, and the percentage of children with serum concentrations exceeding $50 \mathrm{nmol} / 1$ was $70 \cdot 9 \%$. The frequency of consuming vitamin-D supplements and vitamin D-rich food, except cows' milk, was low. Older, non-white, low-income and overweight/obese children need targeted efforts to improve their vitamin D status, especially during winter months. Although supplements can raise serum vitamin D concentrations, it appears that the reported supplementation had only a modest effect on improving serum vitamin D concentrations. Establishing broader fortification protocols and formal recommendations for vitamin D supplementation, especially during winter and spring seasons, among Canadian children may be beneficial.

\section{Acknowledgements}

The authors thank the services of the Research Data Centre, University of Alberta, for providing assistance with accessing the data. At the time of the study, N. D. W. was a recipient of an Alberta Innovates Health Solutions' Health Scholar award.

This research was funded through a Canada Research Chair in Population Health, an Alberta Research Chair in Nutrition and Disease Prevention and an Alberta Innovates Health Solutions Scholarship to P. J. V.

L. L. M. designed the study, decided on the analytical approach, conducted the literature review, analysed and interpreted the data, and drafted the manuscript. Y. Y. and N. D. W. designed the study, decided on the analytical approach, interpreted the data and critically reviewed the manuscript. E. L. F. assisted with the preparation of the manuscript. J. P. E. assisted in data interpretation and critically reviewed the manuscript. P. J. V. designed the study, decided on the analytical approach, interpreted the data and critically reviewed the manuscript. All the authors read, edited and approved the final version.

The authors declare that there are no conflicts of interest.

\section{References}

1. Schmid A \& Walther B (2013) Natural vitamin D content in animal products. Adv Nutr 4, 453-462.

2. Holick MF \& Chen TC (2008) Vitamin D deficiency: a worldwide problem with health consequences. Am J Clin Nutr 87, 1080S-1086S.
3. Calvo MS \& Whiting SJ (2003) Prevalence of vitamin D insufficiency in Canada and the United States: importance to health status and efficacy of current food fortification and dietary supplement use. Nutr Rev 61, 107-113.

4. Weiler HA (2008) VITAMIN D: The current state in Canada. CCFN (Canadian Council of Food and Nutrition) report. https://www. cfdr.ca/Downloads/CCFN-docs/Vitamin-D-Report-final-Aug308-revAug9-_2_.aspx (accessed September 2015).

5. Hanley DA \& Davison KS (2005) Vitamin D insufficiency in North America. J Nutr 135, 332-337.

6. Spiro A \& Buttriss JL (2014) Vitamin D: an overview of vitamin D status and intake in Europe. Nutr Bull 39, 322-350.

7. Holick MF (2004) Vitamin D: importance in the prevention of cancers, type 1 diabetes, heart disease, and osteoporosis. $\mathrm{Am} \mathrm{J}$ Clin Nutr 79, 362-371.

8. Health Canada (2012) Vitamin D and calcium: updated dietary reference intakes. http://www.hc-sc.gc.ca/fn-an/nutrition/ vitamin/vita-d-eng.php (accessed September 2015).

9. Gates A, Skinner K \& Gates M (2015) The diets of school aged Aboriginal youths in Canada: a systematic review of the literature. J Hum Nutr Diet 28, 246-261.

10. Tsiaras WG \& Weinstock MA (2011) Factors influencing vitamin D status. Acta Derm Venereol 91, 115-124.

11. Black LJ, Walton J, Flynn A, et al. (2014) Adequacy of vitamin D intakes in children and teenagers from the base diet, fortified foods and supplements. Public Health Nutr 17, 721-731.

12. Janz $\mathrm{T} \&$ \& Pearson C Vitamin D blood levels of Canadians. Statistics Canada Catalogue no. 82-624-X. http://www.statcan. gc.ca/pub/82-624-x/2013001/article/11727-eng.htm (accessed October 2015).

13. Whiting SJ, Langlois KA, Vatanparast H, et al. (2011) The vitamin D status of Canadians relative to the 2011 Dietary Reference Intakes: an examination in children and adults with and without supplement use. Am J Clin Nutr 94, 128-135.

14. Moore CE, Radcliffe JD \& Liu Y (2014) Vitamin D intakes of children differ by race/ethnicity, sex, age, and income in the United States, 2007 to 2010. Nutr Res 34, 499-506.

15. Omand JA, Darling PB, Parkin PC, et al. (2014) Non-Western immigrant children have lower 25-hydroxyvitamin D than children from Western families. Public Health Nutr 17, 1547-1554.

16. Mansbach JM, Ginde AA \& Camargo CA (2009) Serum 25hydroxyvitamin D levels among US children aged 1 to 11 years: do children need more vitamin D. Pediatrics 124, 1404-1410.

17. Canadian Dermatology Association (2016) Canadian Dermatology Association Position Statement: safe and effective way to maintain adequate levels of vitamin D. http://www.dermatology.ca/wpcontent/uploads/2016/09/Vitamin-D-Position-Statement-2016-E. pdf (accessed March 2016).

18. Health Canada (2016) Food and drug regulations (C.R.C., c. 870), http://laws-lois.justice.gc.ca/PDF/C.R.C.,_c._870.pdf (accessed March 2016).

19. Scientific Advisory Committee on Nutrition (2016) Vitamin D and health. London: SACN. https://www.gov.uk/government/ uploads/system/uploads/attachment_data/file/537616/SACN_ Vitamin_D_and_Health_report.pdf (accessed August 2016).

20. Institute of Medicine (2011) Dietary Reference Intakes for Calcium and Vitamin D. Washington, DC: National Academies Press.

21. Holick MF (2009) Vitamin D status: measurement, interpretation, and clinical application. Ann Epidemiol 19, 73-78.

22. Godel JC (2007) Vitamin D supplementation: recommendations for Canadian mothers and infants. Paediatr Child Health 12, $583-589$.

23. Munasinghe LL, Willows N, Yuan Y, et al. (2015) Dietary reference intakes for vitamin D based on the revised 2010 dietary guidelines are not being met by children in Alberta, Canada. Nutr Res 35, 956-964. 
24. Colapinto CK, Rossiter M, Khan MK, et al. (2014) Obesity, lifestyle and socio-economic determinants of vitamin D intake: a population-based study of Canadian children. Can J Public Health 105, e418-e424.

25. Langlois K, Green-Finestone L, Little J, et al. (2010) Vitamin D status of Canadians as measured in the 2007 to 2009 Canadian Health Measures Survey. Health Rep 21, 47-55.

26. Statistics Canada (2014) User Guide, Health Measure Survey (CHMS): Cycle 3 (2014). Ontario, Canada: Statistics Canada.

27. Statistics Canada (2014) Canadian Health Measure Survey (CHMS). Detailed information for January 2012 to December 2013 (Cycle 3). http://www23.statcan.gc.ca/imdb/p2SV.pl?Function= getSurvey $\&$ SDDS $=5071 \&$ lang $=\mathrm{en} \& \mathrm{db}=\mathrm{imdb} \& \mathrm{adm}=8 \& \mathrm{dis}=2 \# \mathrm{a} 2$ (accessed March 2016).

28. Statistics Canada (2016) CHMS Reference Laboratory, Nutrition Research Division, Analytical Procedure Manual 2016. Client Services Officer, Health Statistics Division, Statistics Canada.

29. Onis MD, Onyango AW, Borghi E, et al. (2007) Development of a WHO growth reference for school-aged children and adolescents. Bull World Health Organ 85, 660-667.

30. Fritzsche J (2015) Temperature trends in Canada. Statistics Canada Catalogue no. 16-002-X. http://www.statcan.gc.ca/ pub/16-002-x/2011001/part-partie2-eng.htm (accessed March 2016).

31. El Hayek J, Pham TT, Finch S, et al. (2013) Vitamin D status in Montreal preschoolers is satisfactory despite low vitamin D intake. J Nutr 143, 154-160.

32. Health Canada (2011) Eating Well with Canada's Food Guide 2011. http://www.hc-sc.gc.ca/fn-an/food-guide-aliment/ choose-choix/advice-conseil/child-enfant-eng.php (accessed January 2016).

33. Public Health England (2016) The eatwell guide. https://www. gov.uk/government/uploads/system/uploads/attachment_data/ file/528200/Eatwell_guide_booklet.pdf (accessed August 2016).

34. Veugelers PJ, Pham TM \& Ekwaru JP (2015) Optimal vitamin D supplementation doses that minimize the risk for both low and high serum 25-hydroxyvitamin D concentrations in the general population. Nutrients 7, 10189-10208.

35. Ekwaru JP, Zwicker JD, Holick MF, et al. (2014) The importance of body weight for the dose response relationship of oral vitamin D supplementation and serum 25 -hydroxyvitamin D in healthy volunteers. PLOS ONE 9, e111265.
36. Moore CE, Murphy MM \& Holick MF (2005) Vitamin D intakes by children and adults in the United States differ among ethnic groups. J Nutr 135, 2478-2485.

37. Girard A \& Sercia P (2013) Immigration and food insecurity: social and nutritional issues for recent immigrants in Montreal, Canada. Int J Migration Health Social Care 9, 32-45.

38. Myres AW \& Kroetsch D (1978) The influence of family income on food consumption patterns and nutrient intake in Canada. Can J Public Health 69, 208-221.

39. Kuhnlein HV, Barthet V, Farren A, et al. (2006) Vitamins A, D, and $\mathrm{E}$ in Canadian Arctic traditional food and adult diets. I Food Comp Anal 19, 495-506.

40. Greene-Finestone LS, Langlois KA \& Whiting SJ (2013) Characteristics of users of supplements containing vitamin D in Canada and associations between dose and 25-hydroxvitamin D. Appl Physiol Nutr Metab 38, 707-715.

41. Webb AR, Kline L \& Holick MF (1988) Influence of season and latitude on the cutaneous synthesis of vitamin $\mathrm{D}_{3}$ : exposure to winter sunlight in Boston and Edmonton will not promote vitamin $\mathrm{D}_{3}$ synthesis in human skin. J Clin Endocrinol Metab 67, 373-378.

42. Veugelers PJ \& Ekwaru JP (2014) A statistical error in the estimation of the recommended dietary allowance for vitamin D. Nutrients 6, 4472-4475.

43. Maxmen A (2011) The vitamin D-lemma. Nature 475, 23-25.

44. Heaney R, Garland C, Baggerly C, et al. (2015) Letter to Veugelers, P.J. and Ekwaru, J.P., A statistical error in the estimation of the recommended dietary allowance for vitamin D. Nutrients 7, 1688-1690.

45. Brett NR, Lavery P, Agellon S, et al. (2016) Dietary vitamin D dose-response in healthy children 2 to 8 y of age: a 12-wk randomized controlled trial using fortified foods. Am J Clin Nutr 103, 144-152.

46. Holick MF, Binkley NC, Bischoff-Ferrari HA, et al. (2011) Evaluation, treatment, and prevention of vitamin D deficiency: an Endocrine Society clinical practice guideline. J Clin Endocrinol Metab 96, 1911-1930.

47. Hall LM, Kimlin MG, Aronov PA, et al. (2010) Vitamin D intake needed to maintain target serum 25-hydroxyvitamin D concentrations in participants with low sun exposure and dark skin pigmentation is substantially higher than current recommendations. J Nutr 140, 542-550. 